\title{
Alleged predatory publisher buys medical journals
}

$\mathrm{O}$ ne of the world's most wellknown "predatory" publishers has bought two commercial Canadian publishers of about 16 medical specialty journals. But one former owner says during the purchasing negotiations, the new publisher agreed not use predatory practices.

The journals were previously published by Pulsus Group in Oakville, Ontario, and Andrew John Publishing in Dundas, Ontario. As of September 28, the journals appear on the Pulsus Group website, which gives an address in London, UK, where Pulsus Group UK was registered in August 2016. It is a subsidiary of OMICS International of Hyderabad, India, which is facing charges from the US Federal Trade Commission (FTC) for "deceiving academics and researchers about the nature of its publications and hiding publication fees ranging from hundreds to thousands of dollars," according to an FTC statement.

Prior to this latest sale, back in December 2015, Pulsus sold four journals to Hindawi, an open-access publisher based in Cairo, Egypt. In June 2016, Pulsus told its remaining journals it was selling them to an unnamed "international publisher," according to Carly Brockington, managing editor of the Canadian Journal of Respiratory Therapy (CJRT). In late August, Pulsus executives told Brockington that Pulsus would merge with Andrew John but they would be run as separate companies.

However, the journals published by Andrew John were told in mid-September they had been sold to iMedPub, a subsidiary of OMICS, says Dr. Stephen Hwang, president of the Canadian Society of Internal Medicine, which owns the Canadian Journal of General Internal Medicine. All the former Pulsus and Andrew John journals now appear on the Pulsus website; the Andrew John website has closed down. Attempts to reach owners of Andrew John for a response were unsuccessful.

Brockington and Hwang were not told that the new publisher was in fact

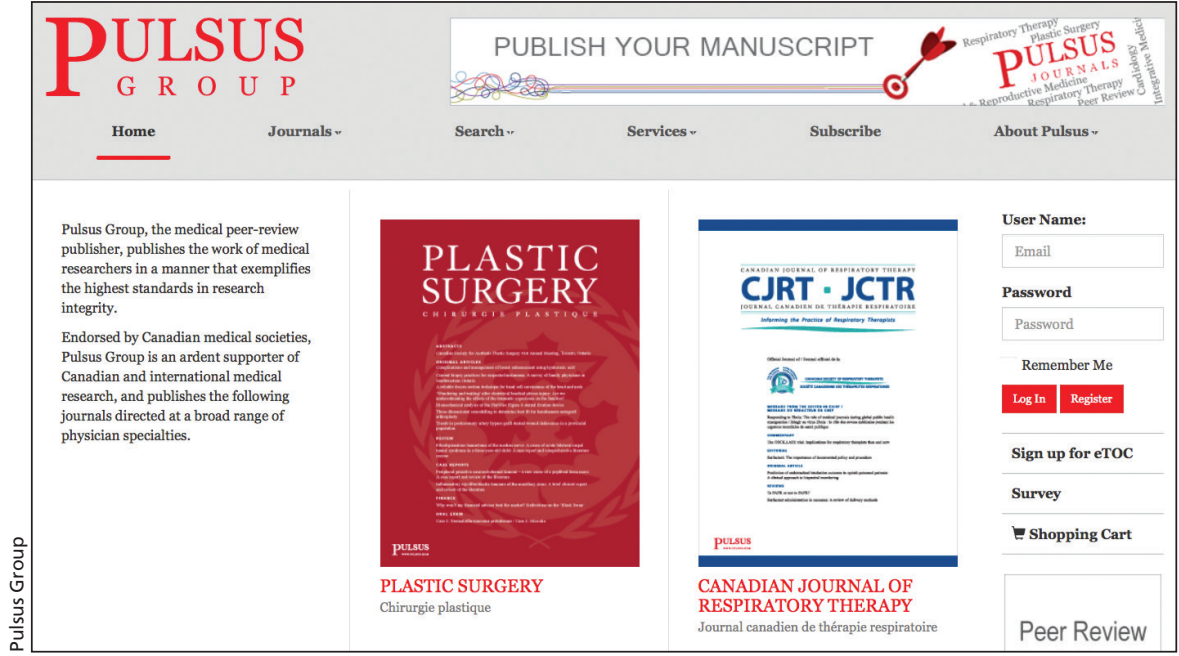

Pulsus journals are now owned by a newly created subsidiary of OMICS International, an alleged predatory publisher based in Hyderabad, India.

OMICS. Brockington learned this during a conference call with the new publisher when she asked who now owned Pulsus Group. When she contacted editors of other Pulsus journals, they were unaware that the new publisher was OMICS.

When Robert Kalina decided to retire after running Pulsus since 1984, he said he searched for potential buyers, but could find "no other takers" for the remaining journals. In an emailed statement he said, "Scientific publishing has been my life and I took great care in crafting an agreement with OMICS that would continue to protect the societies' interests. I would not have trusted selling the name Pulsus to them if I thought otherwise." He stated that he believed OMICS bought Pulsus in order to "start anew" as a legitimate publisher. The FTC charges surfaced after the sale.

Jeffrey Beall, a librarian at the University of Colorado Denver who blogs about predatory publishers, says OMICS' predatory practices are well known. Predatory publishers exploit a fully open access model "for their own gratuitous profit," said Beall. Predatory publishers usually start "counterfeit" journals, and OMICS is the only one that has previously bought legitimate journals, Beall says. "OMICS is not only buying journals, it is buying metrics and indexing," such as the jour- nals' impact factors and listing in Scopus and PubMed, in order to look legitimate, he adds.

Beall says OMICS' main practice is to "hold papers hostage." Authors submit papers in response to spam emails looking for submissions. "The next thing they know the paper has been published and they've got an invoice for $\$ 2000$. They ask to withdraw it, and OMICS won't withdraw it unless you pay a fee." This practice is mentioned in the FTC charges, which also noted "many articles are published with little to no peer review and numerous individuals represented to be editors have not agreed to be affiliated with the journals."

Kalina said that journals are not forced to go to OMICS. "Since most of these journals are owned by the societies, they are, for the most part, free to choose their own publisher. We have offered our help to all societies wishing not to work with OMICS to terminate their agreement," and two journals have asked to terminate.

However, Brockington said CJRT was offered no such assistance. It is now seeking termination of its contract with the help of a lawyer. - Carolyn Brown, Ottawa, Ont.

CMAJ 2016. DOI:10.1503/cmaj.109-5338 